\title{
The causal relationship between natural gas consumption and economic growth: Evidence from the G7 countries"
}

\author{
Tsangyao Chang \\ Department of Finance \\ Feng Chia University, Taichung, TAIWAN \\ Email: tychang@fcu.edu.tw \\ Rangan Gupta \\ Department of Economics \\ University of Pretoria, Pretoria, South Africa \\ Email: rangan.gupta@Up.ac.za \\ Roula Inglesi-Lotz* \\ Department of Economics \\ University of Pretoria, Pretoria, South Africa \\ Email: Roula.inglesi-lotz@Up.ac.za \\ Corresponding author \\ Lilian S. Masabala, \\ Department of Economics \\ University of Pretoria, Pretoria, South Africa \\ Email: lee_masabala@yahoo.com
Beatrice D. Simo-Kengne
Department of Economics
University of Johannesburg, Johannesburg, South Africa
Email: simobeatrice@gmail.com
Jaco P. Weideman,
Department of Economics
University of Pretoria, Pretoria, South Africa
Email: jaco.weideman@outlook.com

\footnotetext{
${ }^{\#}$ We would like to thank an anonymous referee for many helpful comments. However, any remaining errors are solely ours.
} 


\begin{abstract}
:
This paper re-examines the nature of the causality between natural gas consumption and economic growth in G-7 countries over the period from 1965 to 2011 . We employ the Granger causality procedure proposed by Emirmahmutoglu and Kose (2011) which takes into account cross-sectional dependency and heterogeneity across countries. Our overall empirical results support the neutrality hypothesis for the panel while the individual country results confirm the same result with the exception of the case of United Kingdom where the conservation hypothesis is confirmed, showing that GDP causes natural gas consumption in the country. These results make policies that promote the consumption of natural gas risk-free with regards to their effects to the economic growth and development levels.

Keywords: Energy; Natural gas; Economic growth; Panel Granger Causality

JEL Classification: C12, C33, Q4
\end{abstract}

\title{
1. Introduction
}

Developed nations have moved away from wood and other traditional types of power towards natural gas and various types of fossil fuels to meet their energy needs (Stern, 2010). Energy generation may have a negative impact on the environment depending on the source of generation; however, in the current modern global economy, it is considered a factor of production as important as capital or labour affecting the economic capabilities of the countries (Stern, 2010). As Kum et al. (2012) mention, the study of the importance of energy to economic growth must be separated on energy sectors due to the differences between developing and developed countries: the developing countries use more coal than natural gas and the opposite holds for the developed economies. Natural gas is a non-renewable energy source that is considered important for the industrial sector specifically for numerous countries. It is preferable to coal due to its lower carbon-intensity, lower capital costs and higher fuel efficiency (EIA, 2009).

In the literature, four broad hypotheses describe the causal relationship between natural gas and economic growth. The first hypothesis is the conservation hypothesis that states there is 
unidirectional causality running from Gross Domestic Product (GDP) to natural gas consumption. In this case, energy policies aiming at affecting the use of natural gas will have no impact on the economy as a whole. The second hypothesis is the growth hypothesis, according to which the causality runs from natural gas consumption to GDP. Energy policy makers should be sensitive to changes in the natural gas consumption since the effects on the macroeconomy might be severe. The third hypothesis is the feedback hypothesis that assumes bidirectional causality between GDP and natural gas consumption. In other words, energy consumption drives GDP and vice versa. If this hypothesis is confirmed then macroeconomic policies as well as energy policies can affect each other and should be coordinated accordingly. The fourth and final hypothesis is the neutrality hypothesis. This hypothesis implies that there is no relationship at all between energy and GDP growth (Kum et al. 2012).

In relation to the outcomes of previous studies there is no consensus among the four hypotheses. Apergis and Payne (2010) conducted a panel data analysis of 67 countries for the period from 1992 to 2005 concluding that there is a bidirectional causality between natural gas consumption and GDP in the short-run. In a single-country study, Payne (2011) examined the relationship for USA between 1949 and 2006 and confirmed the conservation hypothesis. Reynolds and Kolodziej (2008) looking at the case of the Former Soviet Union in the 1980s and beginning of 1990s confirmed the growth hypothesis; while Lim and Yoo (2012) supported the feedback hypothesis for Korea during the period 1991 to 2008. More recently, for the period from 1970 to 2008, Kum et al. (2012) investigated the group of G7 countries in a trivariate context (including gross capital formation) reporting different results for each of the countries: Causality from natural gas to economic growth for Italy; from economic growth to natural gas for United Kingdom; bidirectional causality for France, Germany and United States; and no causal relationship for Japan and Canada.

Our study here will extend the analysis of Kum et al. (2012) for the G7 countries examining the relationship between natural gas and economic growth for a more recent period from 1965 to 2011 including the recent global financial crisis. This paper improves in a methodological way the one of Kum et al. (2012) in two ways. Firstly, it investigates the countries as a panel as opposed to individually to look for an aggregate relationship. In doing so, the individual circumstances of the countries is no longer allowed to determine the direction of causality, or in 
fact the presence of it to begin with. Secondly, in doing so it also takes account of cross-sectional dependence by employing the causality methodology proposed by Emirmahmutoglu and Kose (2011) which allows us to control for interactions between GDP growth and natural gas consumption and two important econometric issues: the possible cross-sectional dependency and slope heterogeneity across countries. If confirmed, the latter shows that each of these countries, although grouped as the most advanced economies, has different socioeconomic, geographic and political characteristics. However, in an interlinked global environment, economic and other shocks in one country can have a high impact to the rest of the world. This cross-sectional dependency, if confirmed, should not be ignored in a panel data econometric analysis. As Pesaran (2006) states, the omission of these two issues could result in bias and distortions.

The paper proceeds as follows. The next section outlines the methodology and data used. Section 3 presents the empirical results while section 4 concludes with a discussion of policy implications.

\section{Methodology and data}

\subsection{Methodology}

In the current interconnected and open world economy, panel causality analysis ought to take into consideration two important issues: slope heterogeneity and cross-section dependency. Thus, before explaining the causality test, the issues of cross-sectional dependency and heterogeneity of slope coefficients are tested. As mentioned above, shocks originating in one country are likely to spillover onto other countries because of high degree of economic integration across these countries. These spillover effects if ignored, may result in misleading inference due to misspecification. Similar consequences may occur when the homogeneity restriction is imposed to parameters in the presence of cross section specific characteristics (Granger, 2003; Breitung, 2005). Furthermore, unlike traditional causality approaches which rely on cointegration techniques, the bootstrap methodology proposed by Emirmahmutoglu and Kose, (2011) does not require testing for cointegration, hence preventing the issue of pre-test bias (Emirmahmutoglu 
and Kose, 2011). In what follows, we outline the essentials of econometric methods used in this study.

\subsection{Testing cross-sectional dependency}

To test for cross-sectional dependency, the Lagrange multiplier (LM hereafter) test of Breusch and Pagan (1980) has been extensively used in empirical studies. The procedure to compute the LM test requires the estimation of the following panel data model:

$y_{i t}=\alpha_{i}+\beta_{i}^{\prime} x_{i t}+u_{i t}$ for $i=1,2, \ldots, N ; t=1,2, \ldots, T$

where $i$ is the cross section dimension, $t$ is the time dimension, $x_{i t}$ is $k \times 1$ vector of explanatory variables, $\alpha_{i}$ and $\beta_{i}$ are respectively the individual intercepts and slope coefficients that are allowed to vary across states. In the LM test, the null hypothesis of no-cross section dependence- $H_{0}: \operatorname{Cov}\left(u_{i t}, u_{j t}\right)=0$ for all $t$ and $i \neq j$ - is tested against the alternative hypothesis of cross-section dependence $H_{1}: \operatorname{Cov}\left(u_{i t}, u_{j t}\right) \neq 0$, for at least one pair of $i \neq j$. In order to test the null hypothesis, Breusch and Pagan (1980) developed the LM test as:

$$
L M=T \sum_{i=1}^{N-1} \sum_{j=i+1}^{N} \hat{\rho}_{i j}^{2}
$$

where $\hat{\rho}_{i j}$ is the sample estimate of the pair-wise correlation of the residuals from Ordinary Least Squares (OLS) estimation of equation (1) for each $i$. Under the null hypothesis, the $L M$ statistic has asymptotic chi-square with $N(N-1) / 2$ degrees of freedom. It is important to note that the LM test is valid for $\mathrm{N}$ relatively small and $\mathrm{T}$ sufficiently large.

However, the $C D$ test is subject to decreasing power in certain situations that the population average pair-wise correlations are zero, although the underlying individual population pair-wise correlations are non-zero Breusch and Pagan (1980). Furthermore, in stationary dynamic panel data models the CD test fails to reject the null hypothesis when the factor loadings have zero mean in the cross-sectional dimension. In order to deal with these problems, Pesaran et al.(2008) 
propose a bias-adjusted test which is a modified version of the LM test by using the exact mean and variance of the LM statistic. The bias-adjusted LM test is:

$L M_{a d j}=\sqrt{\left(\frac{2 T}{N(N-1)}\right)} \sum_{i=1}^{N-1} \sum_{j=i+1}^{N} \hat{\rho}_{i j} \frac{(T-k) \hat{\rho}_{i j}^{2}-\mu_{T i j}}{\sqrt{v_{T i j}^{2}}}$

where $\mu_{T i j}$ and $v_{T i j}^{2}$ are respectively the exact mean and variance of $(T-k) \hat{\rho}_{i j}^{2}$, that are provided in Pesaran et al. (2008). Under the null hypothesis with first $\mathrm{T} \rightarrow \infty$ and then $\mathrm{N} \rightarrow \infty$, $L M_{a d j}$ test is asymptotically distributed as standard normal.

\subsection{Testing slope homogeneity}

The second issue investigated here is to test whether or not the slope coefficients are homogenous. The causality from one variable to another variable by imposing the joint restriction for the whole panel is the strong null hypothesis (Granger 2003). Moreover, the homogeneity assumption for the parameters is not able to capture heterogeneity due to region specific characteristics (Breitung, 2005).

The most familiar way to test the null hypothesis of slope homogeneity- $H_{0}: \beta_{i}=\beta$ for all $i$ against the hypothesis of heterogeneity- $H_{1}: \beta_{i} \neq \beta_{j}$ for a non-zero fraction of pair-wise slopes for $i \neq j$ - is to apply the standard $F$ test. The $F$ test is valid for cases where the cross section dimension $(\mathrm{N})$ is relatively small and the time dimension $(\mathrm{T})$ of panel is large; the explanatory variables are strictly exogenous; and the error variances are homoscedastic. By relaxing homoscedasticity assumption in the $F$ test, Swamy (1970) developed the slope homogeneity test on the dispersion of individual slope estimates from a suitable pooled estimator. However, both the $F$ and Swamy's test require panel data models where $N$ is small relative to $T$. Pesaran and Yamagata (2008) proposed a standardized version of Swamy's test (the so-called $\tilde{\Delta}$ test) for testing slope homogeneity in large panels. The $\tilde{\Delta}$ test is valid as $(N, T) \rightarrow \infty$ without any restrictions on the relative expansion rates of $\mathrm{N}$ and $\mathrm{T}$ when the error terms are normally 
distributed. In the $\widetilde{\Delta}$ test approach, the first step is to compute the following modified version of the Swamy's test as in Pesaran and Yamagata (2008).

$$
\tilde{S}=\sum_{i=1}^{N}\left(\hat{\beta}_{i}-\tilde{\beta}_{W F E}\right)^{\prime} \frac{x_{i}^{\prime} M_{\tau} x_{i}}{\tilde{\sigma}_{i}^{2}}\left(\hat{\beta}_{i}-\tilde{\beta}_{W F E}\right)
$$

where $\hat{\beta}_{i}$ is the pooled OLS estimator, $\tilde{\beta}_{W F E}$ is the weighted fixed effect pooled estimator, $M_{\tau}$ is an identity matrix, the $\tilde{\sigma}_{i}^{2}$ is the estimator of $\sigma_{i}^{2}$. Then the standardized dispersion statistic is developed as:

$\tilde{\Delta}=\sqrt{N}\left(\frac{N^{-1} \tilde{S}-k}{\sqrt{2 k}}\right)$

Under the null hypothesis with the condition of $(N, T) \rightarrow \infty$ so long as $\sqrt{N} / T \rightarrow \infty$ and the error terms are normally distributed, the $\tilde{\Delta}$ test has asymptotic standard normal distribution. The small sample properties of $\tilde{\Delta}$ test can be improved under the normally distributed errors by using the following bias adjusted version:

$\tilde{\Delta}_{a d j}=\sqrt{N}\left(\frac{N^{-1} \tilde{S}-E\left(\tilde{z}_{i t}\right)}{\sqrt{\operatorname{var}\left(\tilde{z}_{i t}\right)}}\right)$

where the mean $E\left(\tilde{z}_{i t}\right)=k$ and the variance $\operatorname{var}\left(\tilde{z}_{i t}\right)=2 k(T-k-1) / T+1$.

The presence of cross-sectional dependence and heterogeneity over the sample period implies that the panel causality test that imposes the homogeneity restriction and does not account for spillover effects across units may result in misleading inferences; hence providing the rationale of using the bootstrap panel causality approach.

\subsection{Panel Granger Causality analysis}

Emirmahmutoglu and Kose (2011) propose a causality test in heterogeneous mixed panels based on the meta analysis of Fisher (1932). They extended the Lag Augmented VAR (LA-VAR) 
approach by Toda and Yamamoto (1995), which uses the level VAR model with extra dmax lags to test Granger causality between variables in heterogeneous mixed panels. Consider a level VAR model with $k_{i}+d \max _{i}$ lags in heterogeneous mixed panels:

$$
\begin{aligned}
& x_{i, t}=\mu_{i}^{x}+\sum_{j=1}^{k_{i}+d \max _{i}} A_{11, i j} x_{i, t-j}+\sum_{j=1}^{k_{i}+d \max _{i}} A_{12, i j} y_{i, t-j}+\mu_{i, t}^{x} \\
& y_{i, t}=\mu_{i}^{y}+\sum_{j=1}^{k_{i}+d \max _{i}} A_{21, i j} x_{i, t-j}+\sum_{j=1}^{k_{i}+d \max _{i}} A_{22, i j} y_{i, t-j}+\mu_{i, t}^{y}
\end{aligned}
$$

where $i(i=1, \ldots . . N)$ denotes individual cross-sectional units and $t(t=1, \ldots \ldots$.$) denotes time$ periods, $\mu_{i}^{x}$ and $\mu_{i}^{y}$ are two vectors of fixed effects, $\mu_{i, t}^{x}, \mu_{i, t}^{y}$, are column vectors of error terms, $\mathrm{ki}$ is the lag structure which is assumed to be known and may differ across cross-sectional units, and dmaxi is the maximal order of integration in the system for each $i$. Following the bootstrap procedure by Emirmahmutoglu and Kose (2011), testing causality from $\mathrm{x}$ to $\mathrm{y}$ is summarized as follows:

I. Determine the maximal order dmaxi of integration of variables in the system for each cross-section unit based on the Augumented Dickey Fuller (ADF) unit root test and selet the lag orders kis via information criteria (AIC or SB) by esteeming the regression (2) using the OLS method.

II. Re-estimate equation (2) using the dmaxi and ki under the non-causality hypothesis and attain the residuals for each individual.

$$
\hat{u}_{i, t}^{y}=y_{i, t}-\hat{u}_{i}^{y}+\sum_{j=1}^{k_{i}+d \max _{i}} \hat{A}_{21, i j} x_{i, t-j}+\sum_{j=1}^{k_{i}+d \max _{i}} \hat{A}_{22, i j} y_{i, t-j}
$$

III. Residuals are centred using Stine’s (1987) suggestion, i.e.,

$$
\tilde{u}_{t}=\hat{u}_{t}-(T-k-l-2)^{-1} \sum_{t=k+l+2}^{T} \hat{u}_{t}
$$


Where $\hat{\mu}_{t}=\left(\hat{\mu}_{1 t}, \hat{\mu}_{2 t}, \ldots \ldots \ldots, \hat{\mu}_{N t}\right)^{\prime}, \quad k=\max \left(k_{i}\right)$ and $l=\max \left(d \max _{i}\right)$. Next, we develop the $\left[\tilde{\mu}_{i . t}\right]_{N x T}$ from these residuals. We select randomly a full column with replacement from the matrix at a time to preserve the cross covariance structure of the errors. We denote the bootstrap residuals as $\tilde{\mu}_{t}^{*}$ where $(t=1, \ldots, T)$.

IV. A bootstrap sample of y is generated under the null hypothesis, i.e.

$$
y_{i, t}^{*}=\hat{\mu}_{i}^{y}+\sum_{j=1}^{k_{i}+d \max } \hat{A}_{21, i j} x_{i, t-j}+\sum_{j=1}^{k_{i}+d \max } \hat{A}_{22, i j} y_{i, t-j}^{*}+u_{i, t}^{*}
$$

Where $\hat{\mu}_{i}^{y} \quad \hat{A}_{12, i j}$ and $\hat{A}_{22, i j}$ are the estimations from step 3 .

V. For each individual, Wald statistics are calculated to test for the non-causality null hypothesis by substituting $y_{i, t}^{*}$ for $y_{i, t}$ and estimating equation (2) without imposing any parameter restrictions.

VI. Using individual p-values (pi) that correspond to the Wald statistic of the ith individual cross-section, the Fisher test statistic $\lambda$ is obtained as follows:

$$
\lambda=-2 \sum_{i=1}^{N} \ln \left(p_{i}\right) \quad \mathrm{i}=1, \ldots \ldots, \mathrm{N}
$$

VII. The bootstrap empirical distribution of the Fisher test statistics are generated by repeating steps 3 to 510,000 times and specifying the bootstrap critical values by selecting the appropriate percentiles of these sampling distributions.

Using simulation studies, Emirmahmutoglu and Kose (2011) demonstrate that the performance of LA-VAR approach under both the cross-section independency and the cross-section dependency seem be satisfactory for the entire values of $\mathrm{T}$ and $\mathrm{N}$. Note that, to carry out the empirical analysis, we have used the MATLAB $\operatorname{codes}^{1}$ written by Emirmahmutoglu and Kose (2011), which in turn is only limited to a bivariate case, and hence, does not allow us to include additional variables like measures of labour and capital in the production process.

\footnotetext{
${ }^{1}$ The codes are available for download from: http://www.runmycode.org/companion/view/89..
} 


\subsection{Data}

The empirical analysis is carried out using a bivariate approach on G7 countries: Canada, France, Germany, Italy, Japan, UK and US over the sample period 1965 to 2011 . The starting point and the end point of the sample of analysis is purely based on the availability of data on the variables whilst our sample selection is purely driven by the fact that the G-7 are known as being the biggest users of natural gas.

The real GDP annual data are obtained from World Development Indicators of the World Bank (World Bank, 2013). Natural gas consumption (in billion cubic feet) is derived from BP Statistical Review of World Energy (BP 2012). The two variables used in the analysis are employed in their natural logarithms.

Figure 1 plots the evolution of the two variables in average of the G7 countries from 1965 to 2011. It can be noted that the two variables have similar trends through the period investigated increasing at increasing rates in the beginning of the sample but much slower towards the end of the sample. For country specific graphs, look at Figure A1 of the Appendix.

Figure 1: G7 Average GDP (billion US \$) and average natural gas consumption (billion cubic feet).

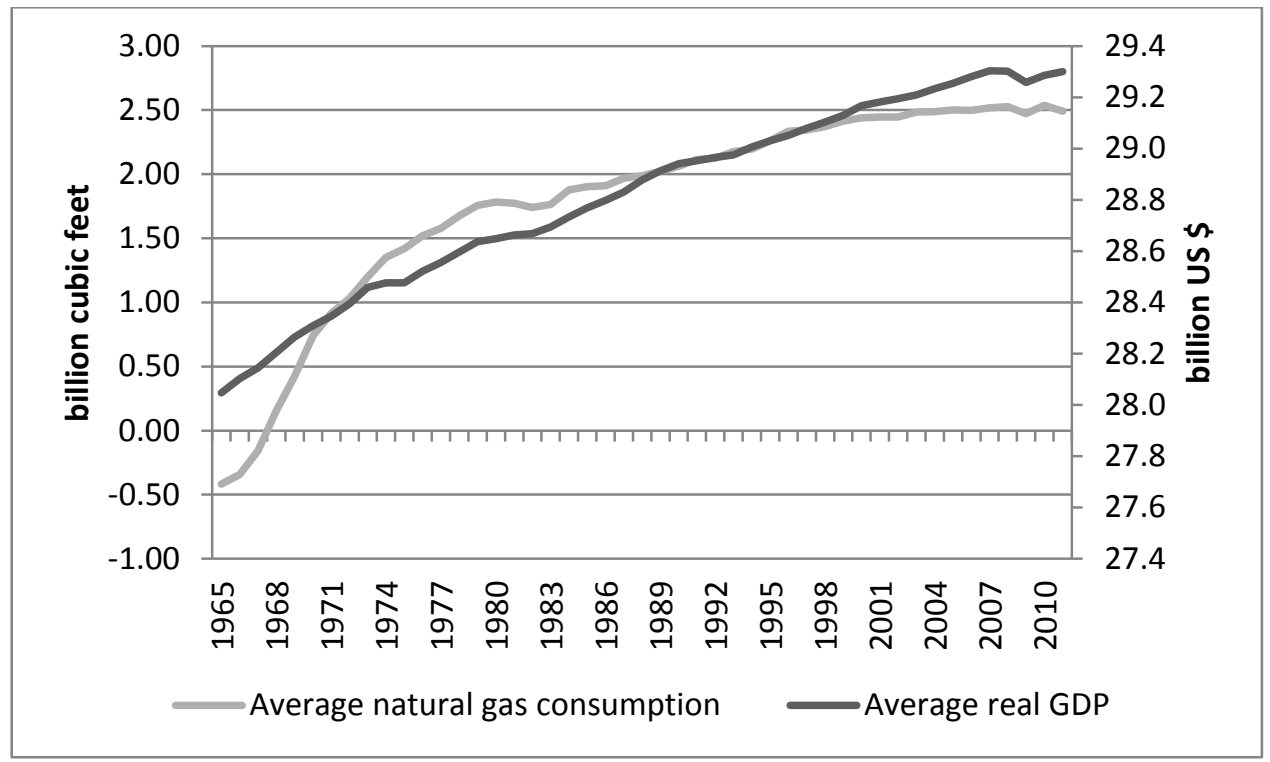

Source: World Bank (2013) and BP (2012) 


\section{Empirical results}

As per the description of the methodology, cross sectional dependency and slope heteregoneity tests are carried out prior to the main Granger causality test. To investigate the existence of cross sectional dependency, we performed four different tests including LM, CDlm, CD, and LMadj. The results are reported in Table 1. It is evident from the results that the null hypothesis of no cross-sectional dependency is strongly rejected in favor of the alternative of cross-sectional dependency at a $1 \%$ level of significance, meaning that a shock originating in one country may spill over onto other countries. This should be taken into account this information when

examining the causal links between natural gas consumption and economic growth. Though $\tilde{\Delta}_{a d j}$ fails to reject the null hypothesis of slope homogeneity in favor of the alternative hypothesis of no homogeneity, both Swamy Shat and $\tilde{\Delta}_{a d j}$ reject the null hypothesis of slope homogeneity, this implies that the panel causality analysis by imposing homogeneity restriction on the variable of interest may result in misleading inferences. Therefore country specific characteristics should be taken into account.

Table 1: Cross-sectional Dependence and Homogeneous Tests (Real GDP and Gas Consumption) - G-7 Countries

\section{Cross-sectional dependency tests}

$C D_{B P}$

$C D_{L M}$

$C D$

$L M_{a d j}$

Slope heterogeneity tests

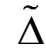

$\tilde{\Delta}_{a d j}$

Swamy Shat
$29.1207 * * *$

0.6532

$140.8845^{* * * *}$

\section{Conclusion}

Cross-Sectional dependency confirmed.

Cross-Sectional dependency confirmed.

Cross-Sectional dependency confirmed.

Cross-Sectional dependency confirmed.

Note: $1 . * * *, * *$, and $*$ indicate significance at the $0.01,0.05$, and 0.1 levels, respectively. 
The establishment of the existence of cross-sectional dependency and heterogeneity across G7 countries suggests the suitability of the bootstrap panel causality approach developed by Emirmahmutoglu and Kose (2011) based on meta-analysis of Fisher (1932) in heterogeneous mixed panels which accounts for these econometric issues. Our bootstrap test causality results are reported in Table 2. The appropriate lag length was chosen based on Schwarz Bayesian (SB) Criterion for each individual country ranging between 1 and 4 .

Table 2: Causality analysis ${ }^{2}$

\begin{tabular}{|c|c|c|c|c|}
\hline \multicolumn{5}{|c|}{ Testing for GDP Granger causing natural gas consumption (Schwarz-Bayesian Criterion) } \\
\hline Country & Lag length & Wald Statistics & p-value & Conclusion \\
\hline Canada & 1 & 1.886 & 0.170 & No causality \\
\hline France & 1 & 0.156 & 0.692 & No causality \\
\hline Germany & 3 & 1.28 & 0.734 & No causality \\
\hline Italy & 1 & 1.434 & 0.231 & No causality \\
\hline Japan & 2 & 5.759 & 0.056 & No causality \\
\hline UK & 3 & $8.934 * *$ & 0.030 & Causality confirmed \\
\hline US & 1 & 0.806 & 0.369 & No causality \\
\hline Fisher test value & \multicolumn{3}{|c|}{ Bootstrap Critical value } & Conclusion \\
\hline \multirow[t]{2}{*}{22.585} & $10 \%$ & $5 \%$ & $1 \%$ & \multirow[b]{2}{*}{ No causality } \\
\hline & 23.304 & 26.638 & 33.738 & \\
\hline \multicolumn{5}{|c|}{ Testing for natural gas consumption Granger causing GDP (Schwarz-Bayesian Criterion) } \\
\hline Country & Lag length & Wald Statistics & p-value & Conclusion \\
\hline Canada & 4 & 2.262 & 0.071 & No causality \\
\hline France & 1 & 0.009 & 0.926 & No causality \\
\hline Germany & 3 & 3.994 & 0.262 & No causality \\
\hline Italy & 1 & 0.206 & 0.650 & No causality \\
\hline Japan & 4 & 3.554 & 0.169 & No causality \\
\hline UK & 4 & 1.298 & 0.730 & No causality \\
\hline US & 2 & 0.220 & 0.639 & No causality \\
\hline Fisher test value & & tstrap Critical value & & Conclusion \\
\hline \multirow[t]{2}{*}{14.067} & $10 \%$ & $5 \%$ & $1 \%$ & No causality \\
\hline & 22.883 & 26.353 & 33.563 & \\
\hline
\end{tabular}

Notes: $\quad 1 . * * *, * *$ and $*$ indicate significance at the $1 \%, 5 \%$ and $10 \%$ respectively.

\footnotetext{
${ }^{2}$ For robustness purposes, we conducted the same analysis using SIC as the choice of lag-length criterion with an increased number of bootstrap to 20,000. The results remain the similar (only in the case of UK no causality running from GDP to natural gas consumption is confirmed)(see Table A1 in the Appendix).
} 
2. Bootstrap critical values are obtained from 10,000 replications.

The overall results for the panel of G7 countries suggest that the null of no Granger causality from economic growth to natural gas consumption and vice versa cannot be rejected (Fisher-test value 22.585 and 14.067 respectively smaller than the Bootstrap critical values).

Moreover individual country results confirm the panel results with the exception of U.K, whose Wald statistic shows that the null hypothesis that the GDP Granger causes natural gas consumption can be rejected at $1 \%$ level of significance. For the rest of the G7 countries, the neutrality hypothesis is validated indicating no causal effect in any direction between natural gas consumption and GDP.

We have now conducted Bai and Perron (2003) multiple structural break tests on the individual countries, as we do not have structural break tests available for the entire panel VAR. Since the break dates were not uniform across countries, we decided to look at the break dates on the average of the two series (Table 3).

Table 3: Structural break analysis

\begin{tabular}{|c|c|c|c|c|c|c|}
\hline Country & $\begin{array}{l}\text { NG } \\
\text { Breaks }\end{array}$ & $\begin{array}{l}\text { NG Break } \\
\text { Dates }\end{array}$ & $\begin{array}{l}\text { GDP } \\
\text { Breaks }\end{array}$ & $\begin{array}{l}\text { GDP Break } \\
\text { Dates }\end{array}$ & $\begin{array}{l}\text { NG Lag } \\
\text { Length }\end{array}$ & $\begin{array}{l}\text { GDP Lag } \\
\text { Length }\end{array}$ \\
\hline CAN & 0 & & 0 & 0 & 1 & 4 \\
\hline FRA & 1 & 1974 & 0 & 0 & 1 & 1 \\
\hline GER & 0 & & 0 & 0 & 3 & 3 \\
\hline ITA & 0 & & 0 & 0 & 1 & 1 \\
\hline JAP & 1 & 1973 & 0 & 0 & 2 & 4 \\
\hline UK & 1 & 1996 & 0 & 0 & 3 & 4 \\
\hline US & 1 & 1987 & 0 & 0 & 1 & 2 \\
\hline Average & 1 & 1972 & 0 & 0 & 1 & 1 \\
\hline
\end{tabular}

Based on SIC and LWZ. Where SIC and LWZ do not agree, BP(2003) sequential methodology used to decide at $5 \%$ significance

Since the average structural break is in 1972, we conducted causality analysis since 1972, taking into account the individual results in Table 3. The results (Table 4) remain the similar (only in the case of UK no causality running from GDP to natural gas consumption is confirmed) 
Table 4: Causality analysis (from 1972)

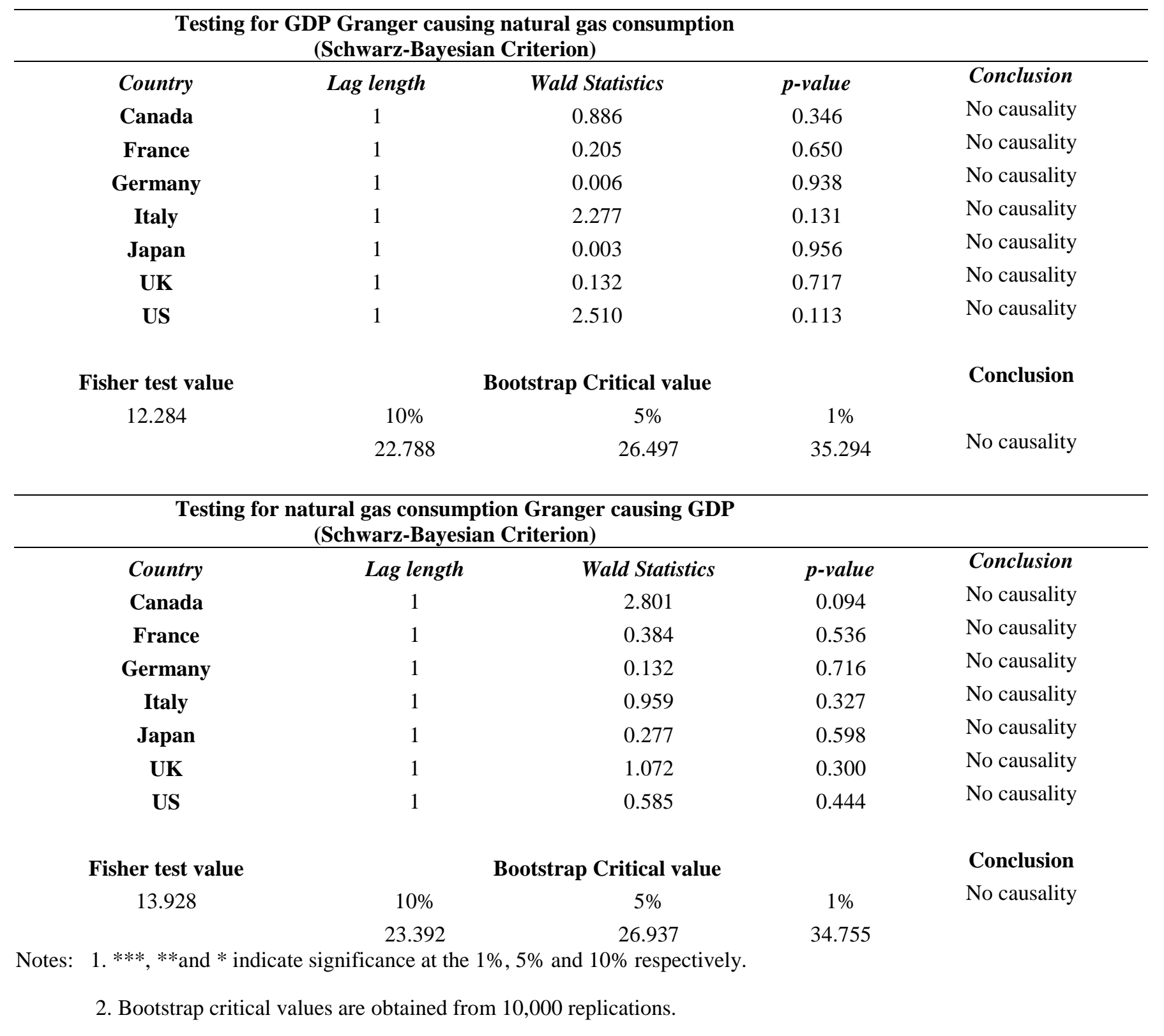

\section{Conclusion}

The bootstrap panel Granger Causality approach as proposed by Emirmahmutoglu and Kose (2011) was employed to test the causal link between natural gas consumption and economic growth for the G7 economies over the period 1965-2011. All in all, the results support the neutrality hypothesis whereby there is no causal relationship between natural gas consumption 
and economic growth, with the exception of U.K. where the conservation hypothesis is confirmed.

The nature of the economies and their energy profile in combination with their individual reliance on natural gas may be a factor explaining the results. The lack of a causal relationship in Canada and Japan was also confirmed by Kum et al. (2012) while the addition of the years during the financial crisis in our sample might be the reason that the causal relationship for France, Germany, U.S., and Italy has lost their strength and importance. Looking at the case of the U.K., our results confirm those of Kum et al. (2012). For this country, it is noted that the primary use of natural gas is for domestic final consumption, for activities such as heating (MacLeay, Harris and Annut, 2013). Since the industry only contributes a small portion to the total natural gas consumption, the role of natural gas as an input in the production process is unlikely and hence does not drive GDP growth.

Natural gas is considered a cleaner and cheaper alternative to other fossil fuels such as coal. It is going to be advantageous for the environmental conditions of countries to promote its use. However, this has to be done without affecting the economic growth and development of the country. Our study, confirming the neutrality hypothesis, allows the energy policy makers to discuss policies promoting the use of natural gas without affecting the countries' economic conditions. For the case of U.K. that is the exception, better economic conditions in the country will improve the natural gas consumption, having thus positive environmental effects from the switch from coal consumption for power generation.

Since we identify structural breaks across many countries at different points in time, future analysis should ideally aim to analyze the causal relationship using a bootstrapped rollingwindow approach, which in turn, would also allow us to get information on time-varying causality. In addition, future research should also be aimed at checking for the sign of the causal relationship, over and above just the direction of the relationship, since this is equally important for policy prescriptions. Though, ideally one should control for additional variables besides GDP and natural gas consumption, the fact that the evidence is weak, adding extra determinants of growth and natural gas is not likely to help our cause. As part of future research, it would be interesting to analyze if there are indirect causal effects by incorporating additional variables like 
employment and capital formation. However, this would entail modifying the bivariate modeling approach of Emirmahmutoglu and Kose (2011) to incorporate more than two variables.

\section{References}

Apergis N, Payne JE. 2010. Natural gas consumption and economic growth: a panel investigation of 67 countries. Applied Energy, 87, 2759-63.

Bélaïd, F. and Abderrahmani, F. 2013. Electricity consumption and economic growth in Algeria: A multivariate causality analysis in the presence of structural change. Energy Policy, 55, 286295.

BP. 2012. Statistical review of world energy. Available at: http://www.bp.com/liveassets/bp_internet/globalbp/globalbp_uk_english/reports_and_publicatio ns/statistical_energy_review_2011/STAGING/local_assets/pdf/statistical_review_of_world_ener gy_full_report_2012.pdf

Breitung, J. 2005. A parametric approach to the estimation of cointegration vectors in panel data. Econometric Reviews 24, 151-173.

Breusch, T. S., and Pagan, A. R. 1980. The Lagrange Multiplier test and its applications to model specification in econometrics. The Review of Economic Studies, 47(1), 239-253.

Fisher, R.A., 1932. Statistical Methods for Research Workers, 4th edition. Oliver and Boyd, Edinburgh.

Emirmahmutoglu, F. and N. Kose. 2011. Testing for Granger Causality in heterogeneous mixed panels. Economic Modelling 28: 870-876.

Granger, C.W.J. 2003. Some aspects of causal relationships. Journal of Econometrics 112, 6971.

Energy Information Administration 2009. International Energy Outlook 2009. www.eia.doe.gov/oiaf/ieo/nat gas.html. 
Kum, H., Ocal, O., Aslan, A. 2012. The relationship among natural gas energy consumption, capital and economic growth: Bootstrap-corrected causality tests from G-7 countries. Renewable and Sustainable Energy Reviews, 16, 2361-2365.

Lim H-J, Yoo S-H. 2012. Natural gas consumption and economic growth in Korea: a causality analysis, Energy sources, Part B: economics. Planning, and Policy, 7(2), 169-76.

MacLeay,I., Harris, K., Annut, A 2013. Digest of United Kingdom Energy Statistics 2013. London: United Kingdom Government Department of Energy and Climate Change.

Payne JE. 2011. US disaggregate fossil fuel consumption and real GDP: an empirical note. Energy Sources Part B: Economics, Planning and Policy;6(1), 63-8.

Pesaran, M. H. 2006. Estimation and Inference in Large Heterogeneous Panels with Multifactor Error Structure. Econometrica 74 (4), 967-1012.

Pesaran, M. H. and Yamagata, T. 2008. Testing slope homogeneity in large panels. Journal of Econometrics 142, 50-93.

Pesaran, M. H., Ullah, A. and Yamagata, T. 2008. A bias-adjusted LM test of error cross-section independence. Journal of Econometrics 11, 105-127.

Reynolds DB, Kolodziej M. 2008. Former Soviet Union oil production and GDP decline: granger-causality and the multi-cycle Hubbert curve. Energy Economics; 30, 271-89.

Stern, D. I. 2010. The Role of Energy in Economic Growth. Australian National University (Working Paper).

Swamy, P.A.V.B. 1970. Efficient inference in a random coefficient regression model. Econometrica 38, 311-323.

Toda, H.Y., Yamamoto, T., 1995. Statistical inference in vector autoregressions with possibly integrated processes. Journal of Econometrics 66, 225-250.

World Bank. 2013. World Development Indicators. Washington, DC. 


\section{Appendix}

Table A1: Causality analysis (Schwarz information criterion SIC, 20,000)

Testing for GDP Granger causing natural gas consumption

(Schwarz information criterion)

\begin{tabular}{|c|c|c|c|c|}
\hline Country & Lag length & Wald Statistics & p-value & Conclusion \\
\hline Canada & 1 & 1.886 & 0.170 & No causality \\
\hline France & 1 & 0.035 & 0.851 & No causality \\
\hline Germany & 3 & 1.082 & 0.781 & No causality \\
\hline Italy & 1 & 1.434 & 0.231 & No causality \\
\hline Japan & 2 & 5.759 & 0.056 & No causality \\
\hline UK & 3 & 6.658 & 0.084 & No causality \\
\hline US & 1 & 0.806 & 0.369 & No causality \\
\hline Fisher test value & \multicolumn{3}{|c|}{ Bootstrap Critical value } & Conclusion \\
\hline 20.010 & $10 \%$ & $5 \%$ & $1 \%$ & \\
\hline & 23.093 & 26.275 & 33.260 & No causality \\
\hline \multicolumn{5}{|c|}{$\begin{array}{l}\text { Testing for natural gas consumption Granger causing GDP } \\
\text { (Schwarz information criterion) }\end{array}$} \\
\hline Country & Lag length & Wald Statistics & p-value & Conclusion \\
\hline Canada & 1 & 3.262 & 0.071 & No causality \\
\hline France & 1 & 0.108 & 0.743 & No causality \\
\hline Germany & 3 & 2.953 & 0.399 & No causality \\
\hline Italy & 1 & 0.206 & 0.650 & No causality \\
\hline Japan & 2 & 3.554 & 0.169 & No causality \\
\hline UK & 3 & 2.830 & 0.419 & No causality \\
\hline US & 1 & 0.220 & 0.639 & No causality \\
\hline
\end{tabular}

Fisher test value

14.779
Bootstrap Critical value $10 \%$
$5 \%$

26.236
Conclusion

$1 \%$

33.220

No causality

Notes: $1 . * * *, * *$ and $*$ indicate significance at the $1 \%, 5 \%$ and $10 \%$ respectively.

3. Bootstrap critical values are obtained from 20,000 replications. 
Figure A1: Real GDP and Natural Gas Consumption across the G7 Countries: 1965-2011
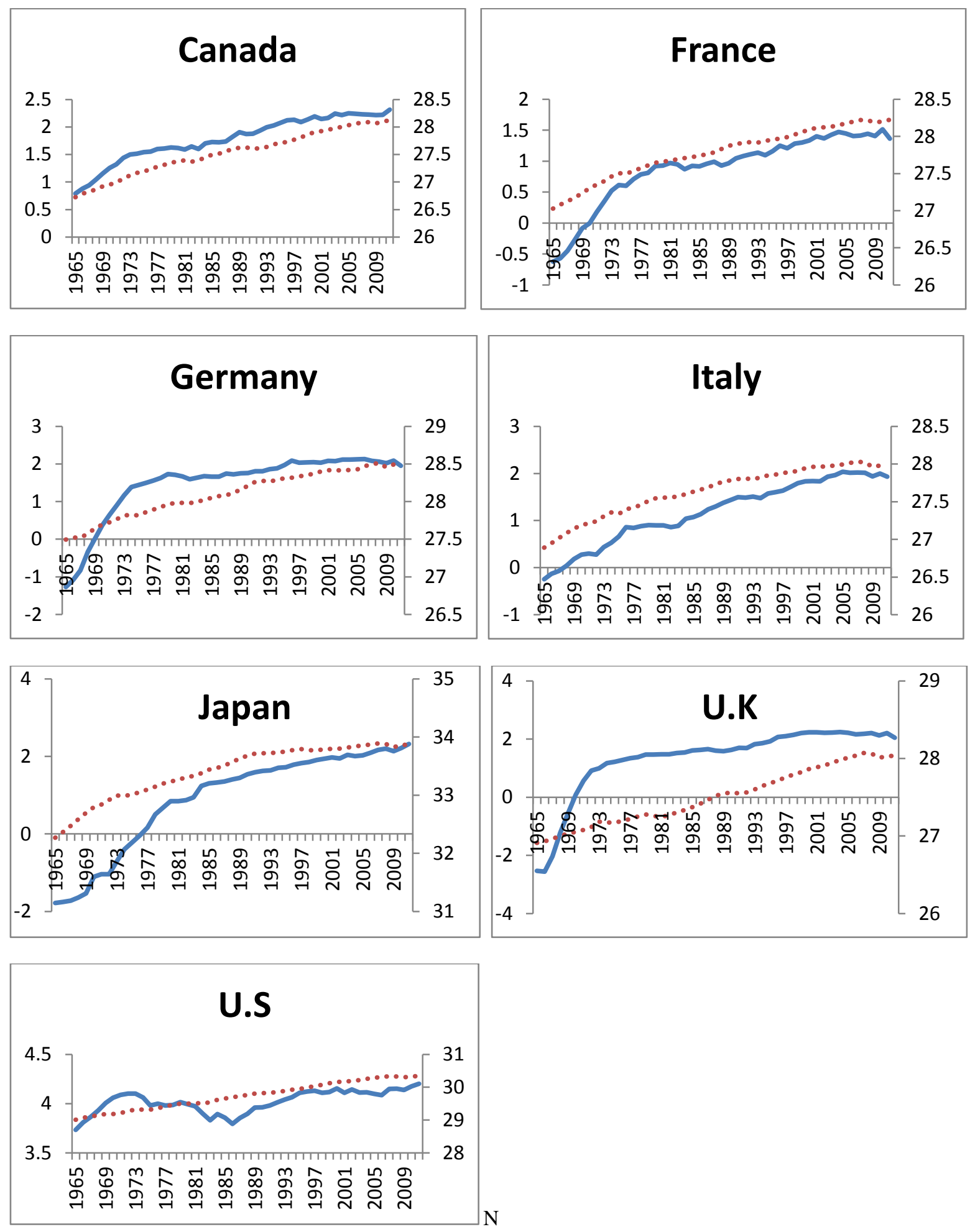

Notes: Natural Gas Consumption (Solid line, scale on the left axis), Real GDP (dotted line, on the right axis). 